\title{
ESTUDO DAS PROPRIEDADES E BIODEGRADABILIDADE DE BLENDAS DE POLIÉSTER/AMIDO SUBMETIDAS AO ATAQUE MICROBIANO
}

\author{
Glória M. Vinhas*, Yêda M. B. de Almeida e Maria Alice Gomes de Andrade Lima \\ Departamento de Engenharia Química, Universidade Federal de Pernambuco, Av. Prof. Artur de Sá, s/n, 50740-521 Recife - \\ PE, Brasil \\ Lívia Almeida Santos \\ Departamento de Ciências Ambientais, Universidade Federal de Pernambuco, 50740-521 Recife - PE, Brasil
}

Recebido em 19/7/06; aceito em 9/3/07; publicado na web em 24/7/07

\begin{abstract}
STUDY OF THE PROPERTIES AND BIODEGRADABILITY OF POLYESTER/STARCH BLENDS SUBMITTED TO MICROBIAL ATTACK. This work deals with the biodegradation of blends of poly( $\beta$-hydroxybutyrate)/starch and poly( $\beta$-hydroxybutyrate-cohydroxyvalerate)/starch. The blends were obtained by evaporation of the solvent in the mixture of the polymers in chloroform. Tests were carried out in presence of micro-organisms which acted as biodegradation agents. The blends were consumed as carbon substrate and the production of $\mathrm{CO}_{2}$ was evaluated in the process. In addition, the polyesters' mechanical properties were reduced by the incorporation of starch in its structure. $\left({ }^{1} \mathrm{H}\right) \mathrm{NMR}$ and infrared spectroscopy detected some characteristic polyester degradation groups in the polyesters' chemical structure, thus confirming the alteration suffered by it.
\end{abstract}

Keywords: biodegradation; fungi; blends.

\section{INTRODUÇÃO}

O desenvolvimento na segunda metade do século XX foi profundamente marcado pelo surgimento dos materiais poliméricos e plásticos, os quais constituem atualmente boa parte dos materiais utilizados pelo homem.

Os plásticos têm papel fundamental na sociedade moderna, mas devido ao fato de algumas aplicações destes materiais serem de descartabilidade muito rápida, associado à grande dificuldade de degradação no ambiente, podendo demorar séculos para se degradar e ocupando grande volume na área dos aterros, têm despertado fortes preocupações nos dias atuais ${ }^{1-7}$.

$\mathrm{O}$ aumento no interesse científico pela área ambiental, atraído pelo crescimento explosivo do consumo de polímeros ou plásticos e pela disposição final destes resíduos sólidos urbanos, tem tornado cada vez mais necessária, a produção de substitutos ambientalmente sustentáveis, importantes no gerenciamento de resíduos, os chamados polímeros ou plásticos ambientalmente degradáveis (PADs), compostos por um vasto grupo de materiais poliméricos, naturais e sintéticos, que sofrem alterações químicas sob a influência de fatores ambientais ${ }^{8}$.

Devido à preocupação mundial em não agredir o meio ambiente, um tipo de material polimérico vem merecendo atenção, os polidroxialcanoatos, principalmente o poli( $\beta$-hidroxibutirato $)$ - PHB e seu copolímero poli(hidroxibutirato-co-valerato)-PHB-HV. A produção desses biopolímeros em grande escala acontece por um processo de fermentação bacteriana, sendo ainda um processo relativamente caro $^{9,10}$.

As blendas poliméricas usando o amido, em mistura com os polímeros biodegradáveis e polímero sintético, surgem como uma boa alternativa para minimizar os custos dos polímeros biodegradáveis, bem como aumentar a biodegradação dos polímeros sintéticos. Além disso, o amido é um material de baixo custo com valor estimado de US\$ $0,50 / \mathrm{kg}^{11}$, sendo uma matéria-prima abundante que permite o desenvolvimento de produtos recicláveis e

*e-mail: gmvinhas@yahoo.com.br quando biodegradado ou incinerado libera $\mathrm{CO}_{2}$ para a atmosfera ${ }^{12}$.

Acredita-se que a mistura do plástico convencional com o polímero biodegradável possa resultar em um material plástico com boas propriedades mecânicas, apresentando resistências ao calor, à luz e à umidade, e que, ao ser descartado, possa ser facilmente degradado por microrganismos cujo habitat natural seja o próprio solo ${ }^{12,13}$. A degradação de um polímero depende da natureza do mesmo e das condições ambientais, as quais podem variar desde a exposição a fatores abióticos (sol, calor, umidade) até a assimilação por um microrganismo vivo (bactérias e fungos).

Os fungos são os principais microrganismos responsáveis pela biodegradação de materiais poliméricos, principalmente dos polímeros de origem natural, tais como amido e celulose. Essa capacidade de degradação dos fungos ocorre pelo fato de produzirem enzimas que hidrolisam esses substratos, os quais servem de materiais nutrientes, sendo este um processo necessariamente aeróbio que libera gás carbônico na atmosfera e devolve ao solo compostos nitrogenados e outros materiais ${ }^{14}$.

Este trabalho teve como objetivo principal avaliar as propriedades de blendas de PHB/amido e PHB-HV/amido antes e após a biodegradação por culturas mistas dos fungos Talaromyces wortmannii e Phanerochaete chrysosporium.

As propriedades avaliadas foram resistência à tração na ruptura, alongamento na ruptura, propriedades morfológicas após a fratura e caracterização química por RMN e infravermelho.

\section{PARTE EXPERIMENTAL}

\section{Materiais}

Polímero

Os poliésteres utilizados foram poli( $\beta$-hidroxibutirato)-PHB e poli( $\beta$-hidroxibutirato-co-valerato) - $\mathrm{PHB}-\mathrm{HV}$, fornecidos pela $\mathrm{PHB}$ Industrial S/A. O amido utilizado foi do tipo regular amidex 3001, fornecido pela Corn Products do Brasil. Os poliésteres e o amido foram utilizados sem nenhum tratamento prévio. 


\section{Reagentes}

Os reagentes utilizados na preparação dos meios, todos da marca Vetec, foram: glicose P.A., cloreto de sódio, agar-agar, peptona bacteriológica, extrato de carne, hidróxido de bário, ácido clorídrico, hidróxido de sódio. Na desinfecção das blendas foi utilizado etanol (Synth).

\section{Microrganismos}

As linhagens de microrganismos utilizadas foram da espécie Phanerochaete chrysosporium $(\mathrm{Ph})$, proveniente da coleção de cultura da Universidade Federal do Rio de Janeiro, conhecida por sua capacidade em degradar lignina e celulose, e uma segunda linhagem selvagem da espécie Talaromyces wortmannii (BM-18), isolada do solo do Aterro da Muribeca (Jaboatão dos Guararapes-PE), natural de solos, pertencente à classe dos Deuteromycetes. É a segunda espécie mais comum do gênero existente em solos.

\section{Métodos}

\section{Manutenção das linhagens de fungos}

As culturas foram mantidas em meio Sabouraud - Ágar com $\mathrm{pH}$ ajustado em 4-5, estocadas a temperatura de $5{ }^{\circ} \mathrm{C}$ e repicadas a cada mês.

\section{Preparação da suspensão de esporos}

Os esporos foram coletados com alça de platina e introduzidos em tubos de ensaio contendo $10 \mathrm{~mL}$ de solução esterilizada de Tween 80 a $0,01 \%$, seguida de agitação. Os esporos foram contados em Câmara de Neubauer e as suspensões ajustadas para $10^{6}$ esporos/mL.

\section{Preparação das blendas}

Os filmes de PHB/amido e PHB-HV/amido na composição 80/ $20 \mathrm{~m} / \mathrm{m}$ e filmes de PHB e PHB-HV puros apresentaram espessuras de $0,07 \pm 0,01 \mathrm{~mm}$, e foram obtidos através da técnica de evaporação do solvente de soluções do polímero em clorofórmio, nas seguintes condições: massa total: $0,98 \mathrm{~g}$; temperatura de controle: $50{ }^{\circ} \mathrm{C}$; tempo total de mistura: $16 \mathrm{~h}$; em sistema sob agitação e após completa dissolução, foram transferidos para placa de Petri (diâmetro de 11 $\mathrm{cm})$ na temperatura ambiente, sem controle da umidade.

\section{Ensaio de biodegradação}

$\mathrm{O}$ monitoramento da produção de $\mathrm{CO}_{2}$ foi realizado em triplicata, segundo o teste de Sturm que consiste de um sistema composto por um compressor de ar, um reator e dois recipientes coletores de $\mathrm{CO}_{2}$, um colocado antes e outro após o reator, todos conectados por mangueiras (Figura 1), contendo 400 e $200 \mathrm{~mL}$, respectivamente, de solução de hidróxido de bário ${ }^{13}$. As soluções de $\mathrm{Ba}(\mathrm{OH})_{2}$ foram preparadas dissolvendo-se 4,8 e 3,2 $\mathrm{g}$ do reagente em 400 e $200 \mathrm{~mL}$ de água destilada, respectivamente, para o primeiro e último recipientes. No reator foram introduzidos $200 \mathrm{~mL}$ de meio de crescimento Sabouraud juntamente com uma amostra da blenda e após 24 h de agitação, na ausência de contaminação, foi inoculado com a cultura mista dos fungos.

A cada $12 \mathrm{~h}$ foram feitas substituições nos últimos recipientes de cada sistema por uma nova solução de hidróxido de bário e o conteúdo substituído foi filtrado sob vácuo. Por retrotitulação com ácido clorídrico, 1 molar, as quantidades de $\mathrm{CO}_{2}$ produzidas na biodegradação e coletadas no recipiente $\mathrm{C}$ foram determinadas segundo cálculos estequiométricos ${ }^{15}$.

Para esse ensaio foi feito também o branco, cujo procedimento foi idêntico ao descrito anteriormente, sem a presença das blendas poliméricas.

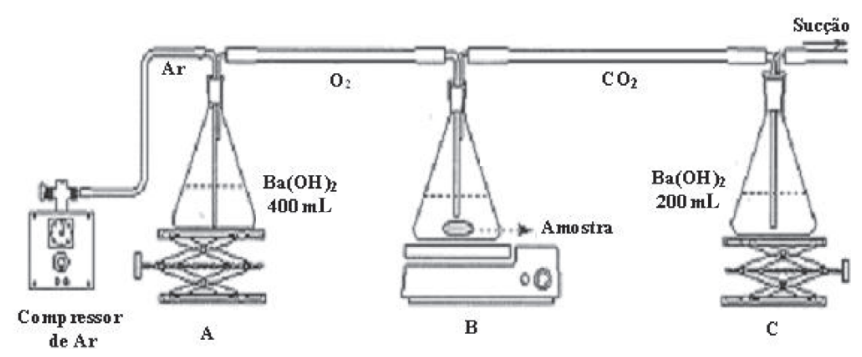

Figura 1. Esquema de montagem para monitoramento da produção do $\mathrm{CO}_{2}$ (Teste de Sturm)

\section{Caracterização das blendas}

Ensaios mecânicos

Os ensaios de resistência à tração na ruptura e o percentual de alongamento na ruptura foram analisados em quintuplicado, em máquina universal de ensaio, marca EMIC de força máxima 500 N, seguindo a ASTM D 638-82a (ASTM, 1982), a temperatura ambiente $\left(\approx 28{ }^{\circ} \mathrm{C}\right)$ e sem controle de umidade, velocidade da garra: $10 \mathrm{~mm} / \mathrm{min}$; distância entre as garras de $35 \mathrm{~mm}$.

\section{Ressonância Magnética Nuclear (RMN)}

Os ensaios de RMN ${ }^{1} \mathrm{H}$ para PHB e PHB-HV puro e suas blendas com amido, antes e após a biodegradação, foram realizados em um espectrômetro Variant Unit Plus-300 em uma frequiência de ressonância de 299,95 e 75,42 MHz, utilizando-se clorofórmio deuterado como solvente.

\section{Espectroscopia no Infravermelho com Transformada de Fourier (FTIR)}

Amostras de PHB/amido e PHB-HV/amido, antes e após a biodegradação, foram secadas e analisadas por infravermelho no equipamento de FT-IR Brucker modelo 1FS66, utilizando a técnica de pastilha de $\mathrm{KBr}$, para avaliação do Índice de Grupos Carboxílicos Terminais (IGCT) através da equação

IGCT $=\left(\right.$ absorção a $\left.3290 \mathrm{~cm}^{-1}\right) /\left(\right.$ absorção a $\left.2970 \mathrm{~cm}^{-1}\right)$ onde: $3290 \mathrm{~cm}^{-1}$ é referente aos grupos carboxílicos terminais; 2970 $\mathrm{cm}^{-1}$ é referente à vibração de deformação axial C-H (pico referência)

\section{Microscopia Eletrônica de Varredura (MEV)}

A região de ruptura das amostras das blendas de $\mathrm{PHB} /$ amido e PHB-HV/amido e do polímero PHB e PHB-HV puro, sem exposição aos microrganismos, foi coberta com uma fina camada de ouro, e sua superfície micrografada em microscópio JEOL JSM-6360 com aumentos de 100 e 250 vezes.

\section{RESULTADOS E DISCUSSÃO}

\section{Teste de Sturm}

A Figura 2 apresenta os resultados da produção de $\mathrm{CO}_{2}$, já considerada a exclusão da massa de $\mathrm{CO}_{2}$ liberada pelo meio de cultura utilizado (branco). O monitoramento da produção de $\mathrm{CO}_{2}$ das blendas de PHB/amido e PHB-HV/amido foi feito a cada $24 \mathrm{~h}$ isoladamente. Pode-se observar que houve uma elevada produção nos primeiros dias. Acredita-se que este comportamento inicial devese ao consumo da glicose presente no meio. Com a diminuição da glicose do meio de crescimento inicial, os fungos passaram a consumir de forma gradativa as blendas poliméricas, como fonte de carbono alternativa. Observa-se também que a partir do décimo dia a produção de $\mathrm{CO}_{2}$ pela blenda $\mathrm{PHB} /$ amido foi maior que a do PHB-HV/amido. 
Rosa e Filho ${ }^{14}$, quando estudaram a biodegradação em compostos orgânicos estabilizados das blendas de PHB/amido e PHBHV/amido com percentuais de 25 e $50 \%$ de amido, também evidenciaram o aumento da degradação das blendas pela presença do amido em sua composição.

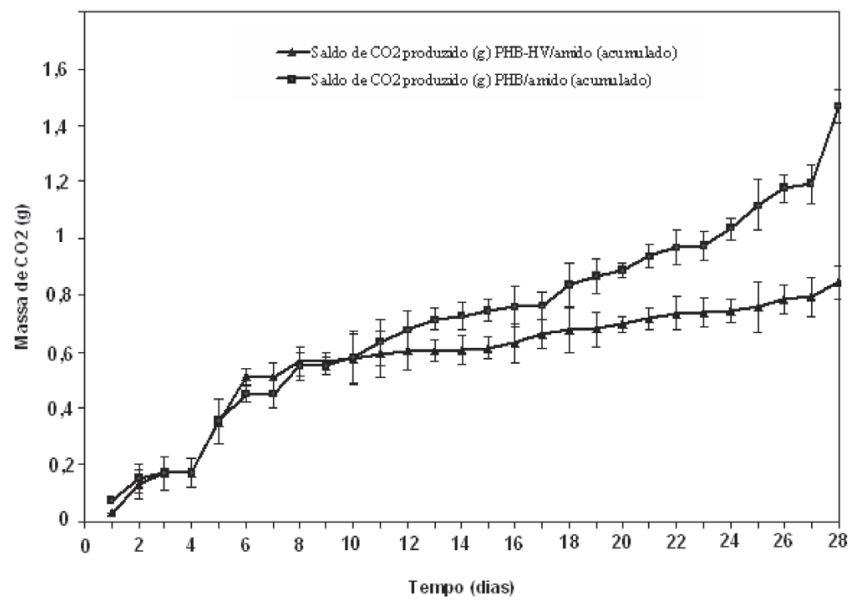

Figura 2. Saldo da produção de $\mathrm{CO}_{2}$ em função do tempo de biodegradação das blendas de PHB/amido e PHB-HV/amido, sob aeração na presença de cultura mista dos fungos Phanerochaete chrysosporium e Talaromyces wortmannii

\section{Ensaios mecânicos}

A Figura 3 e a Tabela 1 fornecem os resultados do comportamento dos filmes submetidos à força mecânica externa; observa-se que os filmes de PHB apresentaram valores de resistência à tração na ruptura superiores aos de PHB-HV. Também pode ser visto que a incorporação do amido ao PHB e PHB-HV promoveu uma redução nos valores da resistência à tração na ruptura. Para o PHB, observa-se uma redução de $30 \%$. Para o PHB-HV a incorporação do amido diminuiu ainda mais sua resistência, transformando-o em filmes muito frágeis, o que impossibilitou a detecção da resistência à tensão na ruptura e o alongamento desse material. Pode-se também observar que o alongamento na ruptura dos filmes de PHB aumentou com a incorporação do amido.

Resultados do ensaio mecânico após a biodegradação não foram possíveis de serem avaliados em função da fragmentação das blendas poliméricas.

Os resultados obtidos nesse trabalho estão de acordo com o que foi obtido por Rosa et al. ${ }^{11}$, que verificaram a influência da incorporação do amido nas propriedades mecânicas em blendas de poliéster/ amido. A resistência à tração do PHB-HV e PHB reduziu de 50 e 40\%, respectivamente, pela incorporação de $25 \%$ de amido na mistura.

\section{Ressonância Magnética Nuclear - RMN}

Nas Figuras 4 e 5 podem ser observados os espectros de RMN ${ }^{1} \mathrm{H}$ das blendas de PHB/amido e PHB-HV/amido antes da

Tabela 1. Resistência à tração na ruptura e alongamento na ruptura do PHB e PHB-HV e suas blendas com amido

\begin{tabular}{lcc}
\hline Polímeros & $\begin{array}{c}\text { Resistência à tração } \\
\text { na ruptura }(\mathrm{MPa})\end{array}$ & $\begin{array}{c}\text { Alongamento } \\
\text { na ruptura(\%) }\end{array}$ \\
\hline PHB & $9,4 \pm 1,6$ & $10,0 \pm 1,0$ \\
PHB/amido & $3,5 \pm 1,0$ & $13,0 \pm 2,4$ \\
PHB-HV & $6,0 \pm 0,9$ & $11,0 \pm 1,7$ \\
\hline
\end{tabular}

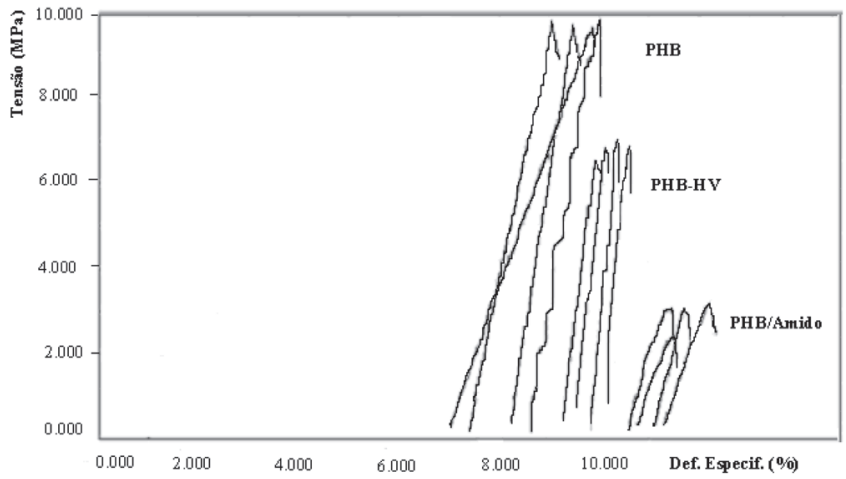

Figura 3. Gráfico da tensão (MPa) em função da deformação específica (\%) para o PHB, PHB-HV e PHB/amido

biodegradação. Os deslocamentos químicos representam posições referentes aos prótons dos poliésteres e do amido, apresentando predominância pela presença do poliéster, dificultando em parte a identificação das estruturas poliméricas individualmente.

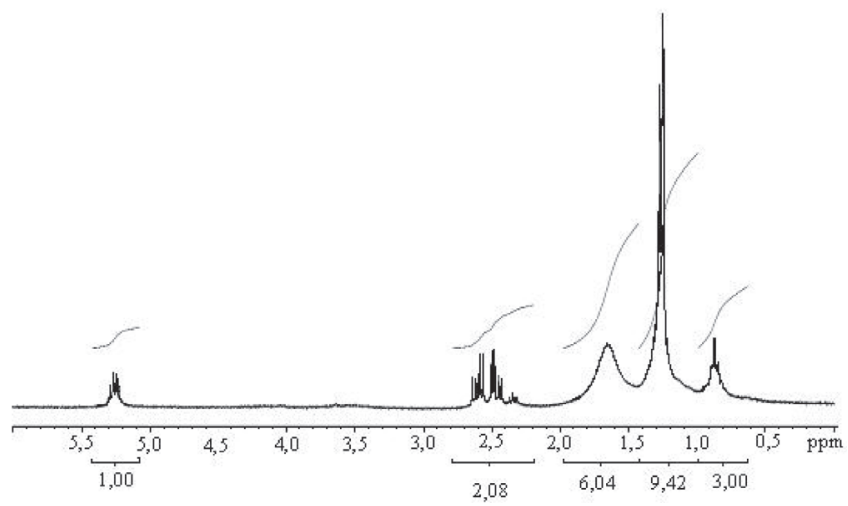

Figura 4. Espectro de $R M N^{l} H$ da blenda de PHB/amido antes da biodegradação

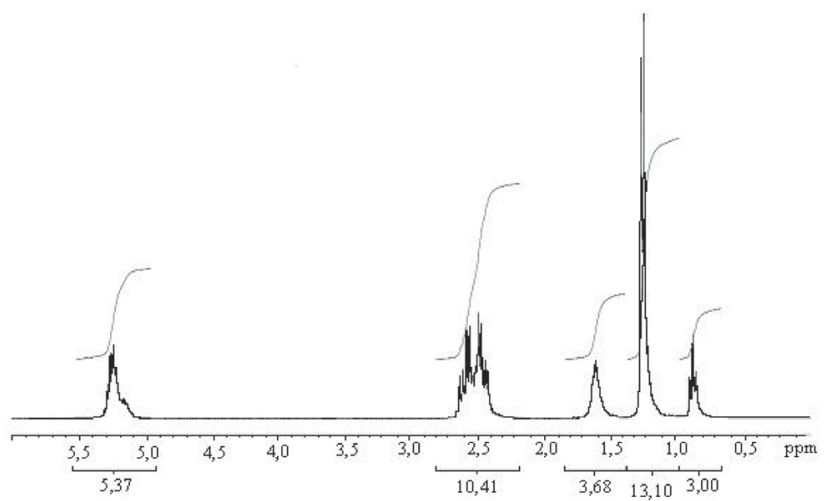

Figura 5. Espectro de $R M N^{l} H$ da blenda de PHB-HV/amido antes da biodegradação

Após a biodegradação observa-se o aparecimento de dois sinais em 3,6 e 4,2 ppm nos espectros do PHB/amido e PHB-HV/amido (Figuras 6,7). O deslocamento químico de 3,6 ppm está associado à formação de novas estruturas terminais, tais como ésteres ou éteres metílicos $\left(\mathrm{CH}_{3}-\mathrm{O}-\right)$, em decorrência de cisão na cadeia lateral do polímero. Por outro lado, cisões no grupo éster da cadeia principal, com perda de monóxido de carbono, contribuem para a formação de grupos terminais alcoólicos, cujo deslocamento químico ocorre em 4,2 ppm. Esses resultados estão de acordo com os obtidos por Olivei$\mathrm{ra}^{15}$ e Luo e Netravali ${ }^{16}$ ao estudarem a degradação radiolítica de PHB. 


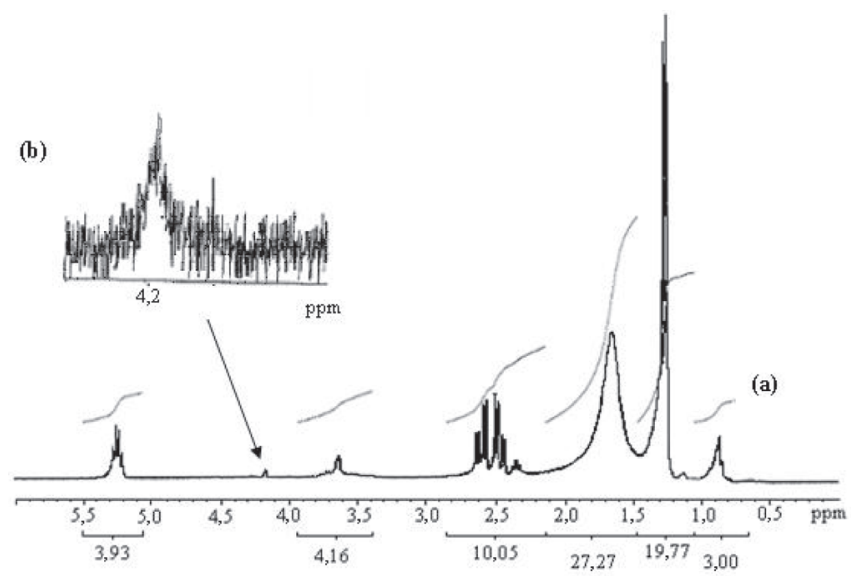

Figura 6. (a) Espectro de $R M N^{1} H$ da blenda de PHB/amido e (b) ampliação do espectro da blenda após a biodegradação

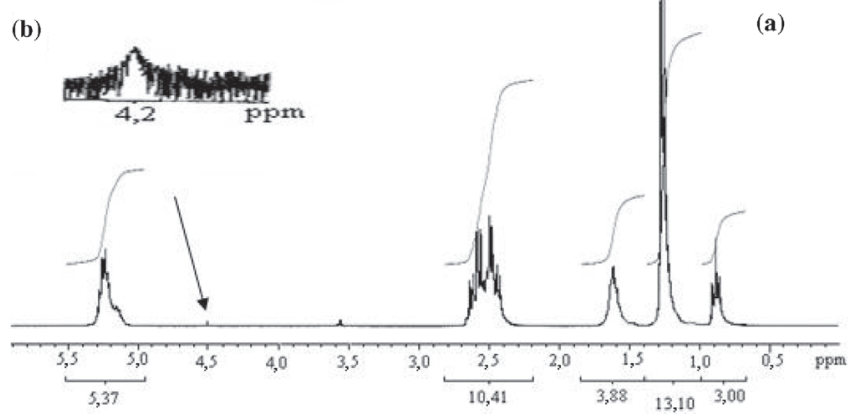

Figura 7. Espectro de $R M N^{1} H$ da blenda de PHB-HV/amido e (b) ampliação do espectro da blenda após a biodegradação

\section{Espectroscopia no Infravermelho com Transformada de Fourier - FTIR}

Uma forma empregada para quantificar a degradação de poliésteres é a determinação da presença de grupos carboxílicos terminais no polímero, uma vez que se entende que a formação desses grupos é decorrente da degradação do poliéster pelo microrganismo. Comparamos amostras de PHB/amido com PHB-HV/amido, antes e após a degradação, como mostra a Tabela 2. Pode-se observar que ocorreu um aumento no IGCT para ambas as blendas, ou seja, após a biodegradação uma maior quantidade de grupos carboxílicos terminais mostraram-se presentes na estrutura química da blenda, caracterizando a formação de grupos carboxílicos terminais e evidenciando a degradação da blenda pelos fungos.

Tabela 2. Índice de Grupos Carboxílicos Terminais

\begin{tabular}{lcc}
\hline Amostra & \multicolumn{2}{c}{ IGCT (\%) } \\
& $\begin{array}{c}\text { Antes da } \\
\text { biodegradação }\end{array}$ & $\begin{array}{c}\text { Depois da } \\
\text { biodegradação }\end{array}$ \\
\hline PHB/amido & 54,51 & 75,91 \\
PHB-HV/amido & 59,34 & 87,38 \\
\hline
\end{tabular}

\section{Microscopia Eletrônica de Varredura - MEV}

A técnica de MEV permite avaliar com detalhes o comportamento mecânico do processo de fratura em experimentos de deformação.

Na Figura 8 são apresentadas as morfologias das fraturas pro- duzidas em ensaio de tração de PHB puro e da blenda de PHB/ amido. Observa-se que o PHB puro (Figura 8a) se comporta como um material rígido, mais compacto, e apresenta uma fratura lisa, característica de um material com menor alongamento antes de romper, sendo portanto mais quebradiço. Por outro lado, a blenda contendo $80 \%$ PHB e $20 \%$ amido (Figuras 8 b e c), apresenta uma superfície de fratura mais rugosa, evidenciada pela formação de "fibrilas", resultado da incorporação do amido, o que confirma os resultados de ensaio mecânico, pois essa blenda sofre uma maior deformação antes da ruptura.

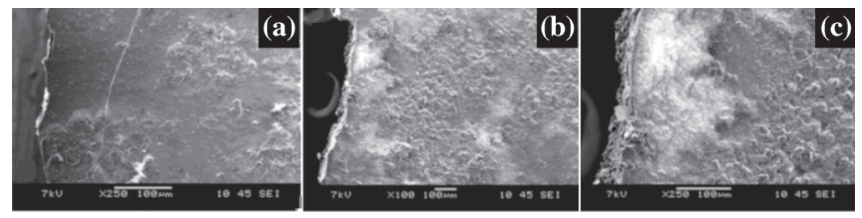

Figura 8. Fotomicrografias da morfologia das fraturas obtidas em ensaios de tração: (a) PHB puro com aumento de 250x; (b) e (c) PHB/Amido com aumento de 100 e $250 x$, respectivamente

Semelhante ao PHB, a superfície de fratura do PHB-HV puro (Figura 9a) mostra-se mais uniforme, compacta e com uma fratura lisa, característica de um material com menor alongamento antes de romper. Já o PHB-HV após a incorporação do amido (Figuras $9 \mathrm{~b}$ e c) apresentou uma superfície mais rugosa, entretanto, sua superfície de fratura não apresentou muita diferença quando comparada com o PHB-HV puro.

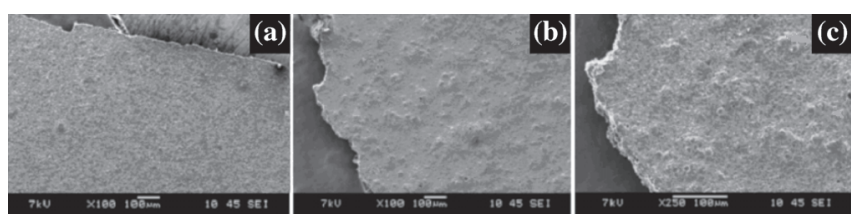

Figura 9. Fotomicrografias da morfologia das fraturas obtidas em ensaios de tração: (a) PHB-HV puro com aumento de 250x; (b) e (c) PHB-HV/amido com aumento de 100 e $250 x$, respectivamente

\section{CONCLUSÕES}

As propriedades mecânicas e morfológicas do PHB e PHB-HV bem como suas blendas com $20 \%$ de amido foram avaliadas antes da biodegradação. Pode-se afirmar que houve uma diminuição nas propriedades mecânicas dos poliésteres com a incorporação do amido.

Apesar da diminuição das propriedades mecânicas pela adição do amido, sua incorporação aos polímeros permite um significativo aumento da biodegradabilidade, possivelmente pela facilidade desse carboidrato ser consumido como fonte alternativa de carbono pelos fungos.

A alteração da estrutura química do polímero pela presença de grupos característicos da degradação dos poliésteres foi confirmada pela espectroscopia de $\mathrm{RMN}\left({ }^{1} \mathrm{H}\right)$ e infravermelho após o ensaio de degradação.

As blendas de PHB/amido e PHB-HV/amido surgem como uma boa alternativa para aplicação em embalagens, pois a presença do amido oferece um custo acessível ao mercado.

\section{AGRADECIMENTOS}

À FACEPE pelo apoio financeiro. Ao CNPq pela concessão de uma bolsa de Iniciação científica a L. A. Santos. Às Indústrias PHB do Brasil AS e Corn Products do Brasil, pelo fornecimento dos poliésteres e do amido. 


\section{REFERÊNCIAS}

1. Jardim, N. S.; Lixo Municipal: manual de gerenciamento integrado, Ed., Instituto de Pesquisas Tecnológicas-CEMPRE: São Paulo, 1995.

2. Chandra, R.; Rustgi, R.; Polym. Degrad. Stab. 1997, 56, 185.

3. Dupret, I.; David, C.; Daro, A.; Polym. Degrad. Stab. 2000, 67, 505.

4. Almeida, U. L.; Aquarone, E.; Borzani, W.; Schidell, W.; Biotecnologia industrial: Processos fermentativos e enzimáticos, Ed. Edgard: São Paulo, 2001.

5. Bonhomme, S.; Cuer, A. ; Delort, A-M.; Lemaire, J. ; Sancelme, M.; Scott, G.; Polym. Degrad. Stab. 2003, 81, 1.

6. Pedroso, A. G.; Rosa, D. S.; Carbohydr. Polym. 2004, 59, 1.

7. Spinacé, M. A. S.; De Paoli, M. A. Quim. Nova 2005, 28, 65.

8. http://labinfo.cefetrs.edu.br/professores/rafael/reciclagem/edps.pdf, acessada em Junho 2006.
9. Chiellini, E.; Solaro, R.; Adv. Mater. 1996, 8, 3.

10. El-Hadi, A.; Schnabel, R.; Straube, E.; Müller, G.; Henning, S.; Polym. Test. 2002, 21, 665

11. Rosa, D. S.; Franco, B. L. M.; Calil, M. R.; Polímeros: Ciência e Tecnologia 2001, 11, 82.

12. Ha, C-S.; Cho, W-J.; Prog. Polym. Sci. 2002, 27, 759.

13. Lima, S. M.; Dissertação de Mestrado, Universidade Federal de Pernambuco, Brasil, 2005

14. Rosa, D. S.; Filho, R. P.; Biodegradação: um ensaio com polímeros, ED. Moara: Itatiba, 2003.

15. Oliveira, L. M.; Tese de Doutorado, Universidade Federal de Pernambuco, Brasil, 2005.

16. Luo, S.; Netravali, N.; J. Appl. Polym. Sci. 1999, 73, 1059 